\title{
Clinical Testing
}

National Cancer Institute

\section{Source}

National Cancer Institute. Clinical Testing. NCI Thesaurus. Code C15791.

Small-scale testing (usually on SBIRs) of new technology in a small group of patients or normal volunteers. Does not meet the rigorous criteria of a clinical trial. 